\title{
Sandostatin, a new analogue of somatostatin, reduces the metabolic changes induced by the nocturnal interruption of continuous subcutaneous insulin infusion in Type 1 (insulin-dependent) diabetic patients
}

\author{
A.J.Scheen ${ }^{1}$, J.Gillet ${ }^{1}$, J. Rosenthaler ${ }^{2}$, J.Guiot ${ }^{1}$, Ph. Henrivaux ${ }^{1}$, B. Jandrain ${ }^{1}$ and P.J. Lefèbvre ${ }^{1}$ \\ ${ }^{1}$ Division of Diabetes, Nutrition and Metabolic Disorders, Department of Medicine, University of Liège, Belgium, and \\ ${ }^{2}$ Department of Biopharmaceutics, Pharma Division, Sandoz LTD, Basle, Switzerland
}

\begin{abstract}
Summary. With the aim of assessing a new somatostatin analogue to prevent the metabolic changes induced by a 6-h nocturnal arrest of an insulin pump, nine C-peptide negative Type 1 (insulin-dependent) diabetic patients were submitted blindly to two interruptions (from 23.00 to 05.00 hours) of their continuous s.c. insulin infusion, once after a single s.c. injection at 23.00 hours of 50 $\mu \mathrm{g}$ SMS 201-995 (Sandostatin, Sandoz) and once after $0.9 \% \mathrm{NaCl}$. Plasma SMS 201-995 levels peaked at 24.00 hours and then declined with an elimination half-life averaging $144 \pm 15$ min. Plasma glucagon and growth hormone levels were significantly reduced after SMS 201-995 whereas the progressive fall in plasma-free insulin levels from 23.00 to 05.00 hours was unaffected. In the control test, blood glucose levels tended to decrease slightly from 23.00 to 02.00 hours and then increased markedly from 02.00 to 05.00 hours $(+5.3 \pm 1.5 \mathrm{mmol} / \mathrm{l})$ while after SMS 201-995
\end{abstract}

they decreased significantly from 23.00 to 02.00 hours ($2.6 \pm 0.5 \mathrm{mmol} / \mathrm{l}$ ), resulting in values below $3 \mathrm{mmol} / 1$ in seven subjects, but showed a secondary increase until 05.00 hours $(+3.5 \pm 1.5 \mathrm{mmol}$ vs $23.00 \mathrm{~h} ; p<0.05$ vs $0.9 \% \mathrm{NaCl})$. While the rises in plasma non-esterified fatty acid and glycerol levels were not reduced by SMS 201-995, the increase in plasma 3hydroxybutyrate levels, although similar from 23.00 to 02.00 hours, was significantly reduced from 02.00 to 05.00 hours $\left(+77 \pm 20\right.$ vs $\left.+124 \pm 31 \mu \mathrm{mol} \cdot \mathrm{l}^{-1} \cdot \mathrm{h}^{-1} ; \quad p<0.05\right)$. Thus, SMS 201-995 significantly reduced the metabolic alterations due to a 6 -h nocturnal interruption of a continuous s.c. insulin infusion but at the cost of a rather high risk of early hypoglycaemia.

Key words: Insulin pump, metabolic deterioration, somatostatin analogue, Type 1 (insulin-dependent) diabetes.
Continuous subcutaneous insulin infusion (CSII) has been proposed with success to improve the metabolic control of Type 1 (insulin-dependent) diabetic patients $[1,2]$. However, although this remains a matter of controversy [2,3], a higher risk of ketoacidotic episodes has been reported with this therapy when compared to the classical treatment with repeated s.c. insulin injections $[4,5]$. This was mainly attributed to technical problems with the pump itself or with the infusion set, resulting in random interruption of the insulin delivery $[6,7]$. Indeed, we have reported previously that the insulin depot in the local subcutaneous tissue was sufficient to allow stopping of the pump for less than $2 \mathrm{~h}$ only $[8,9]$. After a 1-2 $\mathrm{h}$ delay, a 6-h nocturnal interruption of CSII resulted in a rapid and marked metabolic deterioration in initially well-controlled C-peptide negative diabetic patients [10], at least in those with low IgG anti-insulin antibodies [11]. Moreover, we have demonstrated that the linear increases in blood glucose and plasma 3-hydroxybutyrate levels resulting from the CSII interruption could be markedly reduced with a continuous i.v. infusion of natural somatostatin. This reduction probably occurs via the inhibition of glucagon and growth hormone release [12].

For clinical applications, somatostatin has the disadvantages of a short half-life (a few min only) requiring continuous i.v. infusion, of a poor activity after s.c. injection and of multiple non-selective hormone-suppressive effects. A recently synthesized octapeptide analogue of somatostatin (SMS 201-995 or Sandostatin, Sandoz, Basle, Switzerland) has been demonstrated to be more selective in suppressing growth hormone and glucagon secretion [13], to have more prolonged activity [14], to be well-absorbed after s.c. injection [15], and to have a potent hypoglycaemic effect in Type 1 diabetic patients [16].

The aim of the present study was to investigate whether the metabolic alterations induced by a 6-h nocturnal CSII interruption can be prevented by a single s.c. injection of SMS 201-995 in C-peptide negative Type 1 diabetic patients, administered just before the interruption of the pump. 
Table 1. Main characteristics of the patients and their treatment by continuous subcutaneous insulin infusion (CSII)

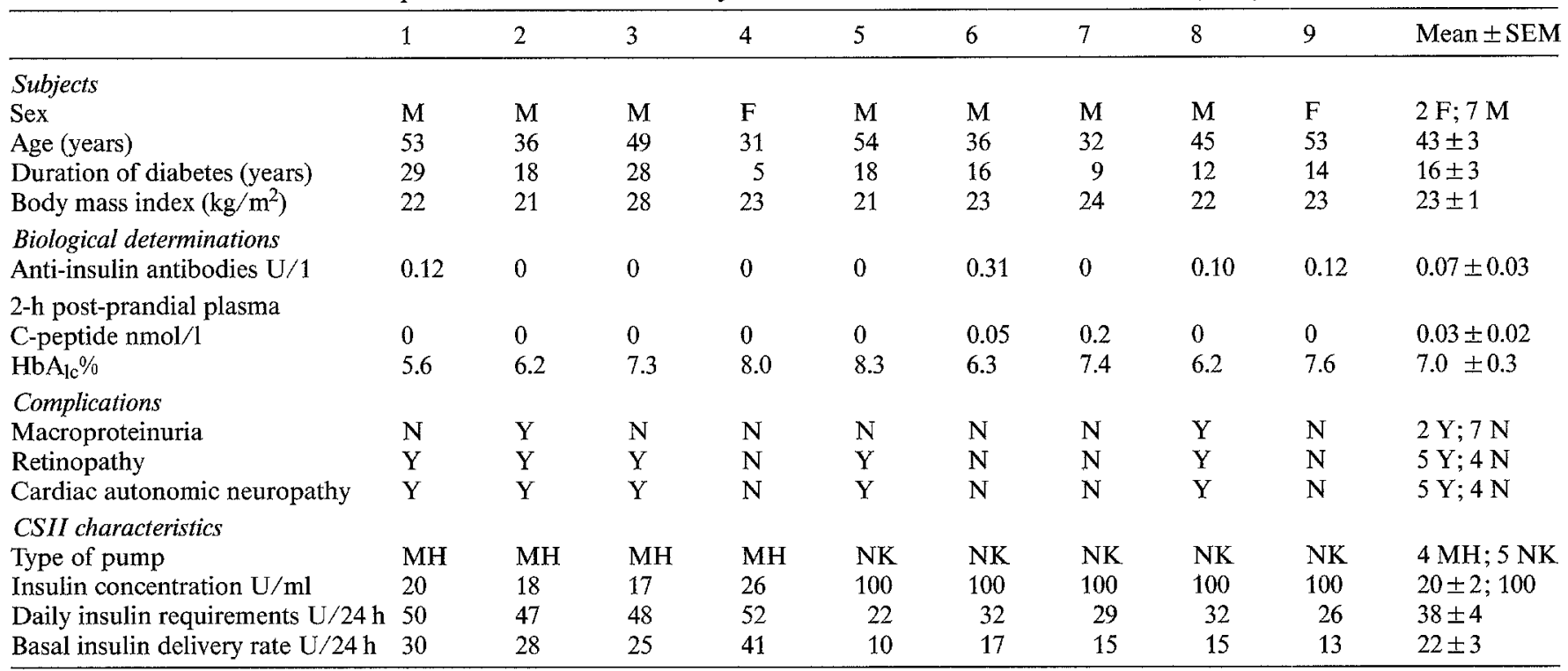

Y: yes; N: no; $\mathrm{MH}=1001 \mathrm{HM}$ Mill Hill Infuser; NK: Nordisk Infuser

\section{Subjects, material and methods}

\section{Subjects}

The study was approved by the Ethical Committee for Human Investigations of the University of Liège, and all subjects gave their free and informed written consent. Nine Type 1 C-peptide negative diabetic patients with low IgG anti-Insulin circulating antibodies participated in the study. Their main characteristics are given in Table 1. Routine biochemical tests including liver enzymes were normal in all subjects. None had increased creatinine serum levels but two patients had macroproteinuria. None presented symptoms or signs of coronary insufficiency, cerebrovascular disease or peripheral arterial disease. However, the retinal examination by direct ophthalmoscopy and fluorescein angiography revealed normal fundus in four patients and (pre)proliferative retinopathy already treated by laser therapy in five patients. In all subjects, the autonomic nervous system function was assessed by the R-R variation during deep breathing at 6 breaths/min according to Ewing et al. [17]. The five patients with the longest duration of diabetes ( $22 \pm 3$ years) and retinopathy showed clearcut abnormally low $\mathrm{R}-\mathrm{R}$ variation, thus indicating the presence of cardiac autonomic neuropathy. In contrast, the four patients with the shortest duration of diabetes $(10 \pm 2$ years) had subnormal $R-R$ variation values. These differences were observed whatever the mode of expression used: standard deviation of the mean R-R interval $(12 \pm 2$ vs $67 \pm 3 \mathrm{~ms}$, $p<0.001$ ), maximum heart rate minus minimum heart rate ( $8 \pm 1$ vs $23 \pm 2$ beats $/ \mathrm{min}, \quad p<0.001$ ) and expiration-to-inspiration ratio $(1.10 \pm 0.01$ vs $1.33 \pm 0.02, p<0.001)$, respectively.

All patients had been treated by CSII for at least several weeks and a fairly good metabolic control was reached as indicated by $\mathrm{HbA}_{10}$ levels which averaged 7.0 $0.3 \%$ (range: 5.6-8.3\%; normal values: $4.0-6.5 \%$ ).

The characteristics of the CSII treatment are described in Table 1. In the four patients using a $1001 \mathrm{HM}$ Mill Hill Infuser (Muirhead Medical, London, UK), insulin (Actrapid HM, $40 \mathrm{U} / \mathrm{ml}$, Novo, Copenhagen, Denmark) was diluted with $0.9 \% \mathrm{NaCl}$ to a final concentration of $20 \pm 2 \mathrm{U} / \mathrm{ml}$ for individual adjustment of basal insulin delivery rate. In the five patients using a Nordisk Infuser (Nordisk, Gentofte, Denmark), the usual cartridge contained insulin at a concentration of $100 \mathrm{U} / \mathrm{ml}$ (Velosulin, $100 \mathrm{U} / \mathrm{ml}$, Nordisk). The basal $(14 \pm 1$ vs $31 \pm 3 \mathrm{U} / 24 \mathrm{~h}, p<0.001)$ and the total $(28 \pm 2$ vs $49 \pm 1 \mathrm{U} / 24 \mathrm{~h}, p<0.001$ ) insulin delivery rates were significantly lower in the patients using the Nordisk Infuser with concentrated insulin than in the patients using the Mill Hill Infuser with diluted insulin.

\section{Experimental procedures}

The experimental protocol was similar to that previously described $[10,12]$. The patients were admitted to the metabolic ward in the afternoon and used the pump at 17.45 hours to deliver their usual pre-dinner insulin dose $(4.0 \pm 0.8 \mathrm{U})$; dinner was taken from 18.00 to 18.30 hours. At 22.00 hours, a catheter was inserted in an antecubital vein. At 23.00 hours, the pump was stopped by removing the battery. At 05.00 hours, the pump was reactivated at its basal rate. At 06.45 hours, the subjects self-administered their usual pre-breakfast insulin boluses $(4.6 \pm 0.4 \mathrm{U})$ plus additional amounts of insulin based on a capillary blood glucose determination (Glucometer II, Ames Division, Miles Laboratories, Elkhart, Ind, USA) and a ketonuria test (Acetest, Ames Division, Miles Laboratories) according to a previously assessed regimen [10]:8 $\mathrm{U}$ if blood glucose was $>22 \mathrm{mmol} / \mathrm{l}$; $6 \mathrm{U}$ if blood glucose was between 16.5 and $22 \mathrm{mmol} / 1$ with ketonuria; $4 \mathrm{U}$ if blood glucose was between 16.5 and $22 \mathrm{mmol} / \mathrm{l}$ without ketonuria; and $2 \mathrm{U}$ if blood glucose was between 11 and $16.5 \mathrm{mmol} / \mathrm{l}$. At 07.00 hours, the patients ate their usual breakfast. At 10.00 hours, the same regimen of insulin supplements was applied if blood glucose was $>11 \mathrm{mmol} / 1$, and the protocol ended at 12.00 hours.

Each subject underwent two tests in a double-blind randomized order at a few days interval: either after a single s.c. injection of $50 \mu \mathrm{g}$ SMS 201-995 at 23.00 hours, just before CSII interruption, or after $0.9 \% \mathrm{NaCl}$ (control test). Insulin regimen and diet were identical during both experimental conditions. Diet consisted of a classical diabetic regimen (52\% carbohydrates, $30 \%$ lipids and $18 \%$ proteins) with a daily caloric intake averaging $1600-2200 \mathrm{kcal}$. The subjects were asleep during the night during both study periods.

\section{Laboratory methods}

Blood samples were drawn every hour from 22.00 until 12.00 hours the next day (except at 11.00 hours). Blood glucose was measured using the hexokinase method adapted to the Technicon Auto Analyzer, plasma non-esterified fatty acids (NEFA) according to Dole and Meinertz [18], plasma 3-hydroxybutyrate (3-OHB) using an enzy- 


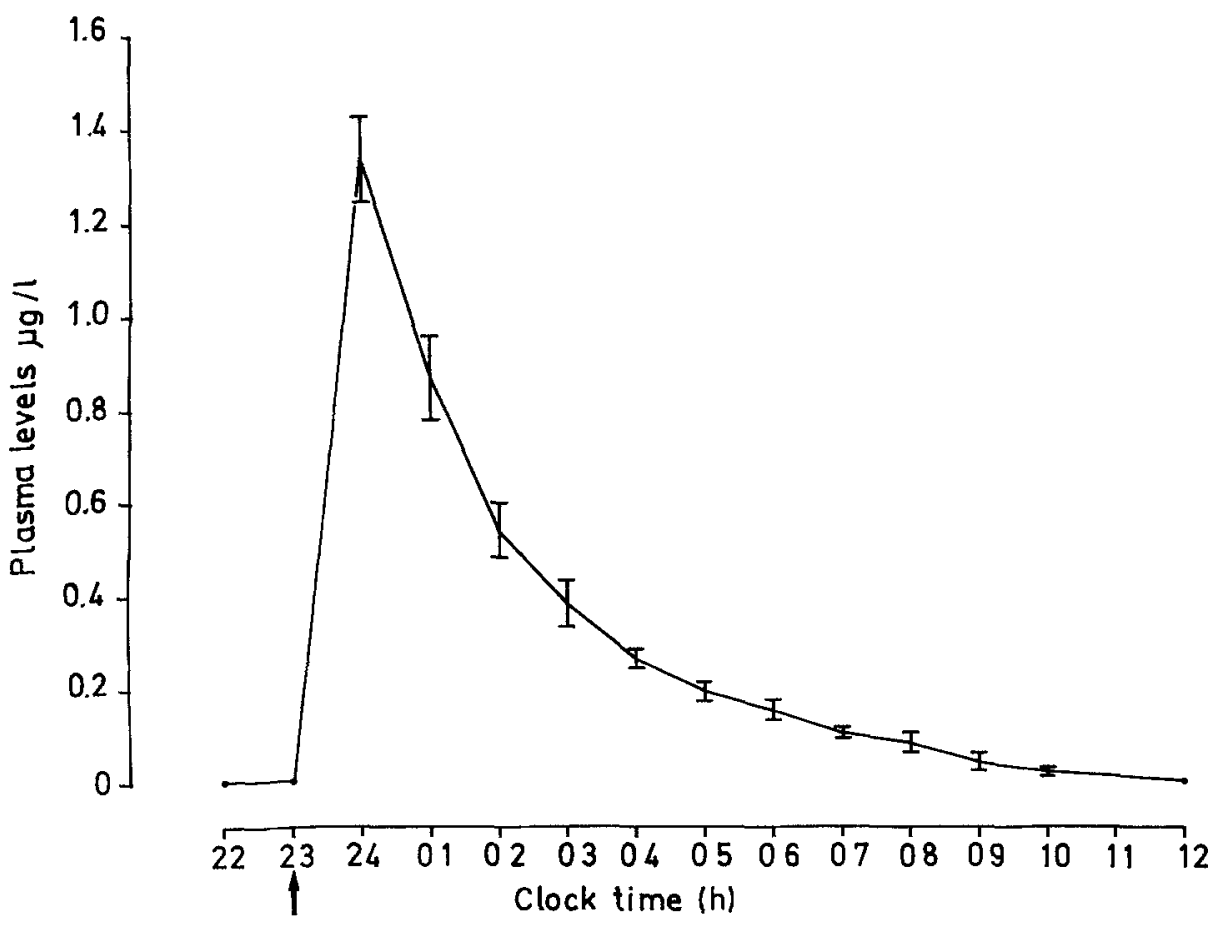

Fig. 1. Plasma concentrations of SMS 201-995 after single s.c. injection of $50 \mu \mathrm{g}$ at 23.00 hours $(\uparrow)$ in nine Type 1 (insulindependent) diabetic patients (mean \pm SEM)

matic assay ( $\beta$-hydroxybutyrate dehydrogenase, Boehringer Mannheim, FRG) according to Williamson and Mellanby [19], plasma glycerol according to Eggstein and Kulhmann [20], plasma glucagon according to Luyckx [21] with Unger's $30 \mathrm{~K}$ antiserum and ${ }^{125}$ I-glucagon obtained from New England Nuclear (Boston, Mass, USA) (inter-assay coefficient of variation (CV):11\%; intra-assay CV:5\%), plasma growth hormone (GH) according to Franchimont [22] (interassay CV:6\%; intra-assay CV:4\%) and plasma-free insulin according to Nakagawa et al. [23] (inter-assay CV:10\%; intra-assay CV:5\%). For all these determinations, samples from both tests collected from the same subject were assayed in the same radioimmunoassay or enzymatic assay series to avoid inter-assay variations. Basal and 2-h postprandial blood samples were drawn from each subject to measure plasma C-peptide according to Heding [24]. Circulating levels of $\mathrm{IgG}$ anti-insulin antibodies were assayed according to Christiansen [25]. $\mathrm{HbA}_{\mathrm{lc}}$ was determined by an isoelectrofocusing method [26]. Plasma concentrations of SMS 201-995 were measured every $h$ from 23.00 to 12.00 hours (except at 11.00 hours) by means of a specific radioimmunoassay as previously described [15].

\section{Statistical evaluation}

The results are expressed as mean \pm SEM. Statistical evaluation was performed according to Student's $t$-test for paired data. All data were compared both between the two experimental conditions and, within a given test, vs the value recorded at 23.00 hours, considered as baseline. For this last comparison, preliminary analysis of variance allowed the subsequent use of Student's $t$-test.

\section{Results}

\section{Plasma SMS 201-995}

The plasma concentrations vs time curve of SMS 201995 after a single s.c. injection of $50 \mu \mathrm{g}$ at 23.00 hours is depicted in Figure 1. In all subjects, peak levels were observed $1 \mathrm{~h}$ after the administration of the drug (no

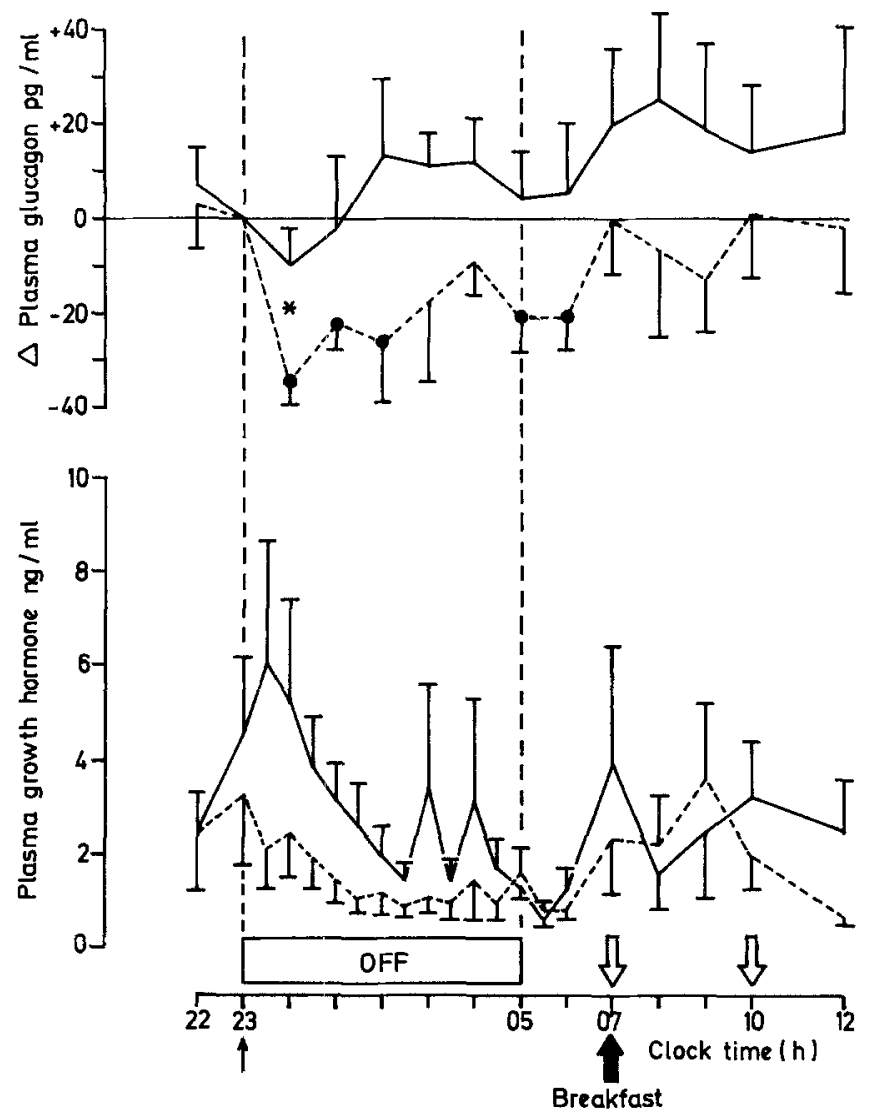

Fig. 2. Plasma glucagon and growth hormone levels before, during and after the interruption of the continuous subcutaneous insulin infusion (OFF) after a single s.c. injection at 23.00 hours $(\uparrow)$ of either SMS 201-995 $50 \mu \mathrm{g}(---)$ or $0.9 \% \mathrm{NaCl}(-)$ in nine Type 1 (insulindependent) diabetic patients. Results are expressed as mean \pm SEM and glucagon values are expressed as changes vs the 23.00 hour value. ${ }^{*} p<0.05$ between the two experimental conditions; $\bullet p<0.05$ vs 23.00 hour value in each test; $\sigma$ s.c. boluses of insulin 


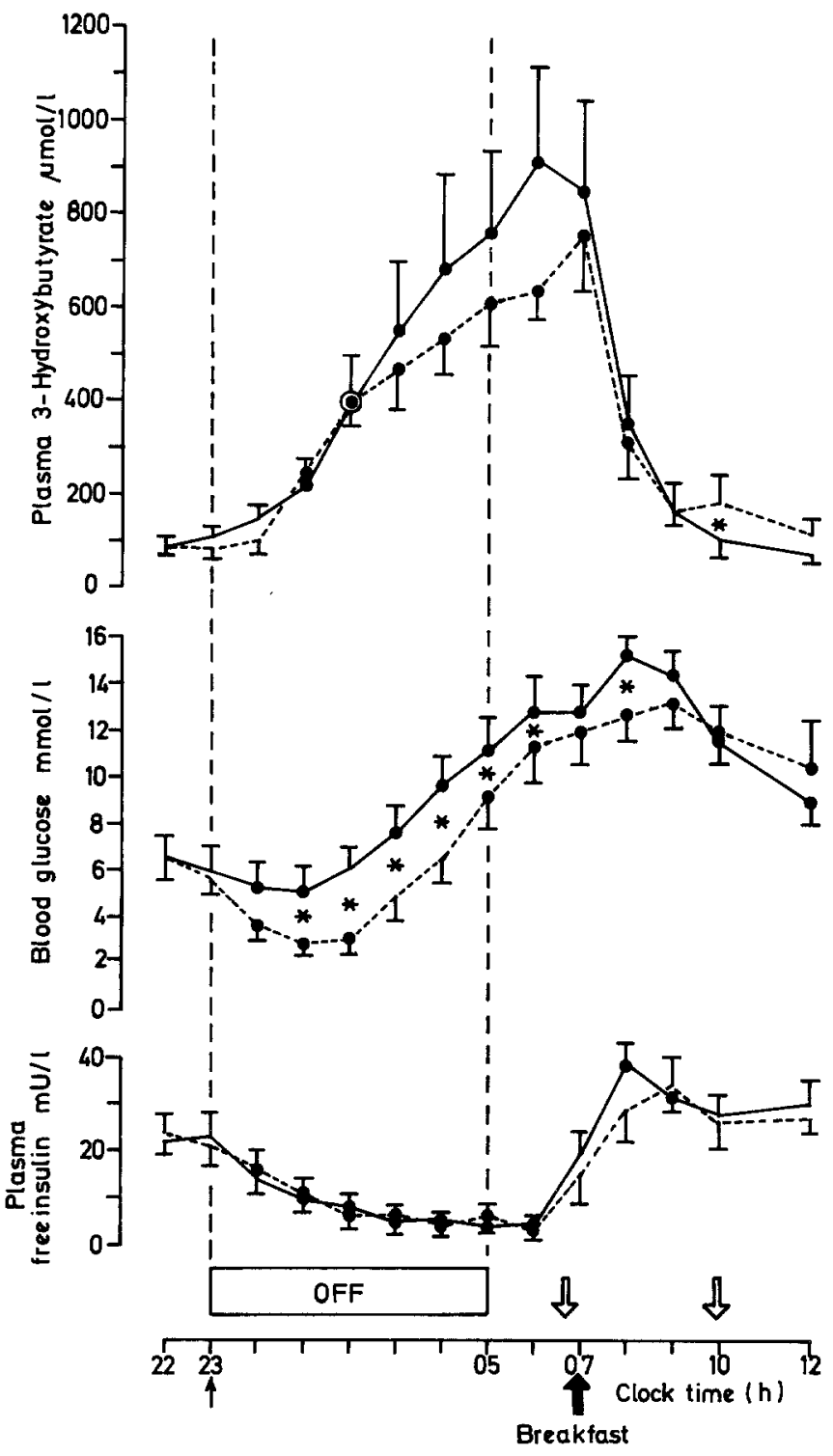

Fig.3. Plasma 3-hydroxybutyrate, blood glucose and plasma-free insulin levels before, during and after the interruption of the continuous subcutaneous insulin infusion (OFF) after a single s.c. injection at 23.00 hours $(\uparrow)$ of either SMS 201-995 $50 \mu \mathrm{g}(---)$ or $0.9 \% \mathrm{NaCl}(-)$ in nine Type 1 (insulin-dependent) diabetic patients. Results are expressed as mean \pm SEM. ${ }^{*} p<0.05$ between the two experimental conditions; $\bullet p<0.05$ v 23.00 hour value in each test; $\nabla$ s.c. boluses of insulin

sampling before) and averaged $1.34 \pm 0.10 \mu \mathrm{g} / 1$ (range $0.85-1.78$ ). Thereafter, plasma levels decreased biphasically according to a degenerated two-compartment model. The calculated half-life (B-phase) for the terminal slope averaged 144 $\pm 15 \mathrm{~min}$ (range: $104-239 \mathrm{~min}$ ). The area under the curve from time 0 ( 23.00 hours) to infinity averaged $4.21 \pm 0.39 \mu \mathrm{g} \cdot \mathrm{h} / \mathrm{l}$ (range: $3.01-5.81$ ).

\section{Plasma glucagon and $G H$}

Initial plasma glucagon levels were similar in both tests: $128 \pm 42 \mathrm{pg} / \mathrm{ml}$ before SMS $201-995$ vs $110 \pm 34 \mathrm{pg} / \mathrm{ml}$ before $9 \% \mathrm{NaCl}(\mathrm{NS})$. In the control test, plasma gluca- gon concentrations tended to increase slightly until the end of the study. In contrast, plasma glucagon levels were significantly lower $1 \mathrm{~h}(-35 \pm 5 \mathrm{pg} / \mathrm{ml} ; p<0.001$ vs level at 23.00 hours and $p<0.05$ vs level at 24.00 hours after $9 \% \mathrm{NaCl}$ ), as well as $2,3,6$ and $7 \mathrm{~h}$ after SMS 201-995 injection (Fig. 2).

Due to marked variability of time and values of individual plasma GH peaks, no significant differences were observed when comparing the nocturnal hourly measurements of the plasma levels of this hormone. However, the maximal individual peak of plasma GH (at whatever time it occurred between 23.00 and 05.00 hours) was significantly lower after SMS 201-995 than after $9 \% \mathrm{NaCl}: 3.7 \pm 0.9$ vs $10.8 \pm 3.0 \mathrm{ng} / \mathrm{ml}$ $(p<0.05)$. Furthermore, after SMS 201-995, the area under the GH plasma concentration-time curve from 23.00 to 05.00 hours was about half that observed in the control test: $9.2 \pm 2.2 \mathrm{vs} 18.5 \pm 3.7 \mathrm{ng} \cdot \mathrm{h} / \mathrm{ml}$ $(p<0.05)$.

\section{Plasma-free insulin}

No significant differences in plasma-free insulin levels were observed between the two tests at any time of the study period. Mean plasma free insulin concentrations, decreased significantly already $1 \mathrm{~h}$ after stopping the pump and reached their nadir at the end of CSII interruption in both tests. Because of the lower capillary glucose levels at 06.45 hours (see below) and the lower additional amounts of insulin administered before breakfast in the SMS 201-995 test $(6.8 \pm 1.2 \mathrm{U}$ vs $8.8 \pm 0.7 \mathrm{U}$, NS), the resulting increase in plasmafree insulin measured from 06.00 to 08.00 hours was slightly but not significantly lower in the test with SMS 201-995 (Fig. 3).

\section{Blood glucose and plasma 3-OHB}

Blood glucose levels averaged $6 \mathrm{mmol} / \mathrm{l}$ at the beginning of both tests. In the control test, they decreased slightly during the first $2 \mathrm{~h}$ of interruption and began to increase significantly only $4 \mathrm{~h}$ after stopping the pump, and in a linear manner until 05.00 hours. Despite CSII interruption at 23.00 hours, injection of SMS 201-995 resulted in a marked decrease in blood glucose concentration until 02.00 hours $(-2.6 \pm 0.5$ $\mathrm{mmol} / \mathrm{l}, p<0.001)$; five of the nine subjects displayed glycaemic values below $2.5 \mathrm{mmol} / 1$ but none of them exhibited symptoms and required glucose or glucagon administration (Fig.3). These patients were characterized by already significantly lower initial blood glucose levels (at 23.00 hours: $4.4 \pm 0.6$ vs $7.3 \pm 0.7$ $\mathrm{mmol} / 1, p<0.02)$. Thereafter, blood glucose rose linearly until 05.00 hours. However, at this moment, blood glucose levels remained significantly lower after 


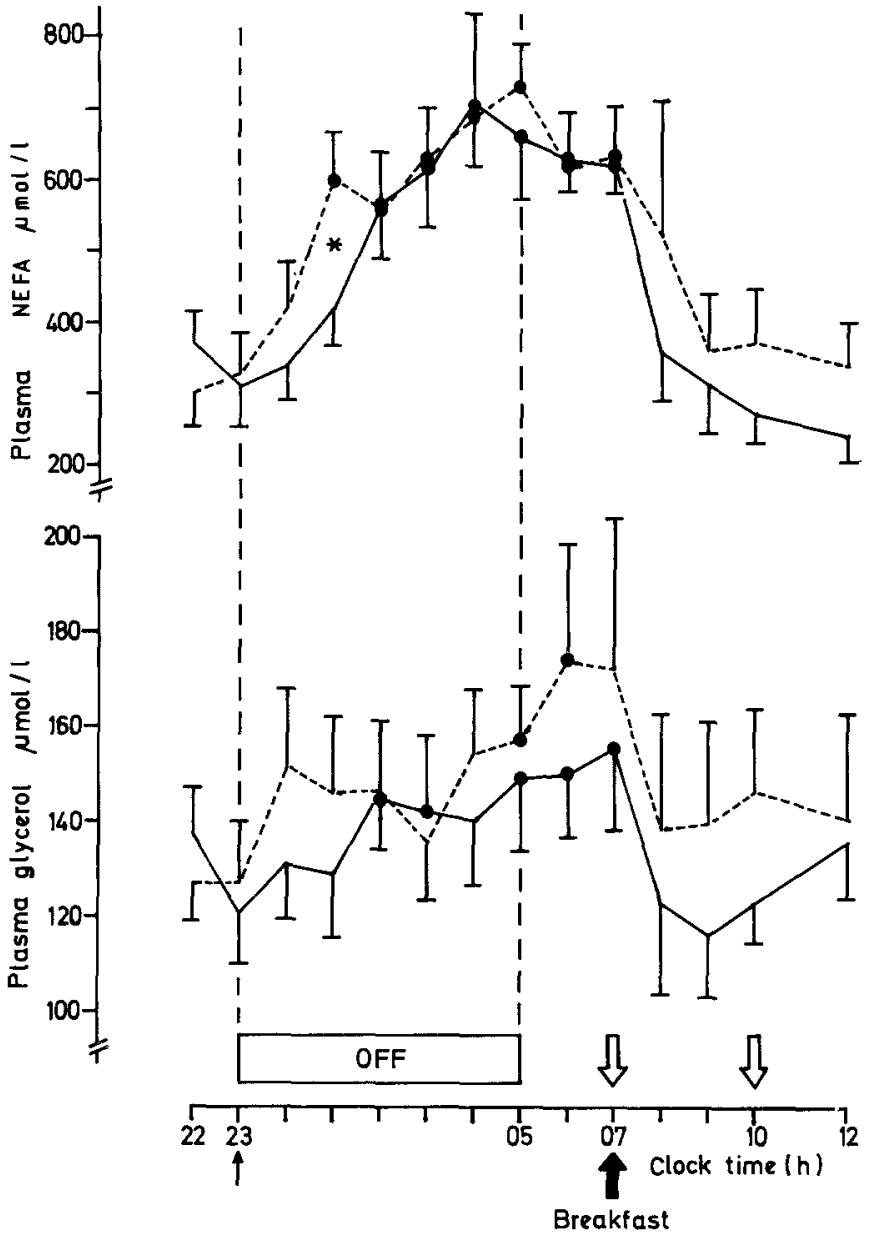

Fig.4. Plasma non-esterified fatty acid (NEFA) and glycerol levels before, during and after the interruption of the continuous subcutaneous insulin infusion (OFF) after a single s.c. injection at 23.00 hours

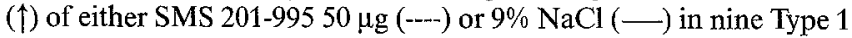
(insulin-dependent) diabetic patients. Results are expressed as mean \pm SEM. $* p<0.05$ between the two experimental conditions; - $p<0.05$ v 23.00 hour value in each test; $\rightarrow$ s.c. boluses of insulin

SMS 201-995 than after $0.9 \% \mathrm{NaCl}: 9.2 \pm 1.3 \mathrm{vs}$ $11.3 \pm 1.4 \mathrm{mmol} / 1 \mathrm{respectively,} p<0.05$. Thus, the $6 \mathrm{~h}$ of CSII interruption can be divided in two parts (Table 2): from 23.00 to 02.00 hours, the rate of change in blood glucose averaged zero in the control test while a rapid decrease was observed after SMS 201995; in contrast, from 02.00 to 05.00 hours the rate of increase in blood glucose was substantial in both tests and was even slightly but not significantly greater after SMS 201-995 than after $0.9 \% \mathrm{NaCl}$. Adjustment of insulin boluses before breakfast resulted in similar blood glucose levels in both experimental conditions during the last part of the test (09.00-12.00 hours).

Initial plasma 3-OHB levels were similarly low, around $100 \mu \mathrm{mol} / 1$, during both tests. During the control test, plasma 3-OHB concentrations were significantly greater $2 \mathrm{~h}$ after the arrest of the pump and then rose regularly until 06.00 hours, when they reached almost $1000 \mu \mathrm{mol} / 1(p<0.01)$. In the test performed after SMS 201-995, the kinetics of the 3-OHB rise was similar to that observed after $0.9 \% \mathrm{NaCl}$ during the first $3 \mathrm{~h}$ after interruption of the CSII. In contrast, from 02.00 to 06.00 hours, plasma 3-OHB levels increased more slowly than in the control test to reach only about 600 umol/1. Consequently, the $6 \mathrm{~h}$-period of CSII interruption can again be divided in two parts (Table 2): from 23.00 to 02.00 hours the rate of increase of 3-OHB was similar in both tests, whereas from 02.00 to 05.00 hours it was significantly lower after SMS 201-995 than after $0.9 \% \mathrm{NaCl}$. After breakfast and insulin boluses, plasma 3-OHB concentrations fell dramatically in both tests to return to their initial values at the end of the study period.

\section{Plasma NEFA and glycerol}

In both tests, plasma NEFA levels averaged $300 \mu \mathrm{mol} / 1$ at 23.00 hours, increased progressively to reach about $700 \mu \mathrm{mol} / 1$ at 05.00 hours $(p<0.01)$, and fell rapidly to reach initial values after breakfast and insulin supplements, between 09.00 to 12.00 hours (Fig.4). Comparison of plasma NEFA levels between the two tests showed only a single statistically significant difference at $01.00 \mathrm{~h}: 608 \pm 68$ after SMS 201-995 vs $428 \pm 51 \mu \mathrm{mol} / 1$ after $0.9 \% \mathrm{NaCl}, p<0.05$. Plasma glycerol concentrations increased progressively from 23.00 to 05.00 hours in both experimental conditions and rapidly declined after breakfast and insulin boluses. Although no significant differences were observed between the two tests at any time of the study period, plasma glycerol levels tended to be higher 1-2 $\mathrm{h}$ after injection of SMS 201-995 than after $0.9 \% \mathrm{NaCl}$.

Table 2. Rate of change in blood glucose and plasma 3-hydroxybutyrate levels during nocturnal interruption of a continuous subcutaneous insulin infusion (CSII) from 23.00 to 05.00 hours in nine Type 1 (insulin-dependent) diabetic patients. The 6-h period of pump arrest was divided in two parts: from 23.00 to 02.00 hours and from 02.00 to 05.00 hours

\begin{tabular}{|c|c|c|c|}
\hline & \multicolumn{3}{|c|}{ Rate of change } \\
\hline & \multicolumn{2}{|c|}{$23.00-02.00$ hours } & $02.00-05.00$ hours \\
\hline & \multicolumn{2}{|c|}{$0.9 \% \mathrm{NaCl}$ SMS 201-995 } & $0.9 \% \mathrm{NaCl}$ SMS 201-995 \\
\hline $\begin{array}{l}\text { Blood } \\
\text { glucose } \\
\mu \mathrm{mol} \cdot 1^{-1} \cdot \mathrm{h}^{-1}\end{array}$ & $\begin{array}{l}+53 \\
( \pm 184) \\
\mathrm{NS} \\
\quad L p<0\end{array}$ & $\begin{array}{l}-866 \\
( \pm 183) \\
p<0.005 \\
.005\lrcorner\end{array}$ & \begin{tabular}{ll}
+1708 & +2033 \\
$( \pm 362)$ & $( \pm 396)$ \\
$p<0.005$ & $p<0.001$ \\
\multicolumn{2}{c}{$\mathrm{NS}\rfloor$}
\end{tabular} \\
\hline $\begin{array}{l}\text { Plasma } \\
\text { 3-OH-butyrate } \\
\mu \mathrm{mol} \cdot 1^{-1} \cdot \mathrm{h}^{-1}\end{array}$ & $\begin{array}{l}+70 \\
( \pm 19) \\
p<0.01 \\
\quad \text { LNS }\end{array}$ & $\begin{array}{l}+107 \\
( \pm 24) \\
p<0.005\end{array}$ & $\begin{array}{ll}+124 & +77 \\
( \pm 31) & ( \pm 20) \\
p<0.005 & p<0.005 \\
\quad\llcorner p<0.05\end{array}$ \\
\hline
\end{tabular}

Results are expressed as mean ( \pm SEM). Statistical comparison has been performed by paired $t$-test and concerns both the changes occurring in each period studied and the differences between the two experimental conditions investigated. 3-OH-butyrate $=3$-hydroxybutyrate 

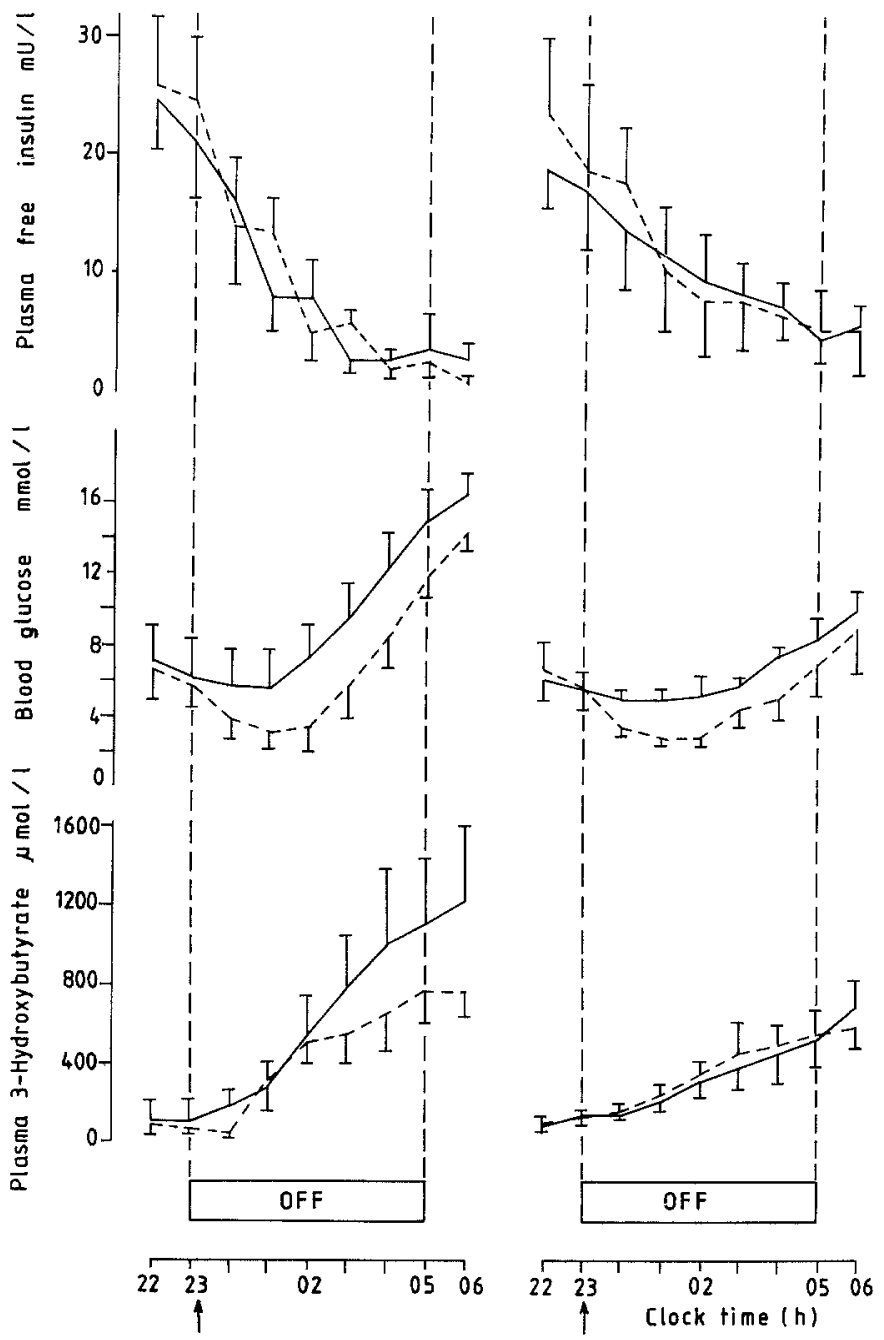

Fig.5. Plasma free insulin, blood glucose and plasma 3-hydroxybutyrate levels before, during and after the interruption of the continuous subcutaneous insulin infusion (OFF) after a single s.c. injection at

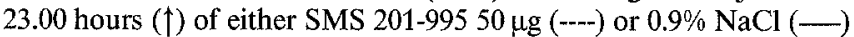
in four patients using the Mill Hill HM 1001 infuser (left panel) and in five patients using the Nordisk infuser (right panel). Results are expressed as mean $\pm \mathrm{SEM}$

\section{Comparison Mill Hill Infuser vs Nordisk Infuser}

Changes in plasma free insulin, blood glucose and plasma 3-OHB levels observed during CSII interruption in patients using either the Mill Hill or the Nordisk infuser are compared in Figure 5. However, owing to the rather small number of patients in each group, no statistical analysis was performed.

During the control test, and when compared to patients using the Mill Hill infuser, the fall in plasmafree insulin levels tended to be slower and smaller in patients using the Nordisk infuser so that they exhibited a delayed and less marked metabolic deterioration. After SMS 201-995, the early fall in blood glucose levels was similar with both types of pumps while, as in the control test, the late increase was reduced in the Nordisk infuser group when compared to the Mill Hill infuser group. As far as plasma 3-OH $\beta$ levels were concerned, the late increase was reduced by the somatostatin analogue only in the group of patients using the Mill Hill infuser, who showed the highest rise in the control test.

The overall increases in plasma glucagon, NEFA and glycerol levels observed in the control test during CSII interruption tended to be slightly greater in the Mill Hill infuser group than in the Nordisk infuser group. The effects of SMS 201-995 on these parameters and on plasma GH levels were similar in both groups of patients.

\section{Comparison patients with vs without autonomic neuro- pathy}

The metabolic deterioration occurring during the 6-h nocturnal CSII interruption was similar in patients having markedly reduced $R-R$ variation during deep breathing and in those with subnormal heart-rate respiratory control. After SMS 201-995 injection, the early 23.00-02.00 hours fall in blood glucose levels was similar in the patients with $(-2.3 \pm 0.8 \mathrm{mmol} / \mathrm{l})$ and without $(-2.9 \pm 0.8 \mathrm{mmol} / \mathrm{l})$ cardiac autonomic neuropathy (NS). The late $02.00-05.00$ hours increase in blood glucose levels $(+6.7 \pm 1.8 \mathrm{vs}+5.3 \pm 1.7 \mathrm{mmol} / 1$, $\mathrm{NS})$ and in plasma $3-\mathrm{OHB}$ concentrations $(+259 \pm$ 90 vs $+193 \pm 85 \mu \mathrm{mol} / 1$, NS) were not significantly different between the two groups of patients, respectively. Similarly, no significant differences were observed in the changes of plasma NEFA, glycerol, glucagon, GH and free insulin levels between the patients with and without autonomic neuropathy in both experimental conditions.

\section{Side-effects}

Except initial asymptomatic hypoglycaemia, no clinical or biochemical side-effects were observed throughout the study period after SMS 201-995.

\section{Discussion}

The experiments reported herein demonstrate that a single s.c. injection of $50 \mu \mathrm{g}$ SMS 201-995 can reduce the metabolic deterioration induced by a 6 -h nocturnal CSII interruption in Type 1 diabetic patients. In fact, the effect observed in the present study is quite similar to that previously described by our group with an i.v. infusion of natural somatostatin at a constant rate of $250 \mu \mathrm{g} / \mathrm{h}[12]$.

The pharmacokinetic characteristics of SMS 201995 in our Type 1 diabetic patients (early peak, elimination half-life, area under the curve) were comparable to those described in healthy volunteers after s.c. injection of the same $50 \mu \mathrm{g}$ dose of the drug [15, 
27]. Moreover, comparison of the i.v. and s.c. routes of administration has shown the absolute bioavailability of SMS 201-995 to be about $100 \%$ after $50 \mu \mathrm{g}$ given s.c. [15]. In our Type 1 diabetic patients, the interindividual coefficients of variation of the main pharmacokinetic parameters ranged between $20-30 \%$ and were well within the known limits in normal subjects $[15,27]$.

SMS 201-995 does not significantly influence the fall in plasma-free insulin levels induced by the 6-h CSII interruption but induced an early fall in plasma glucagon levels and an almost complete suppression of the nocturnal GH peaks. The late decrease in plasma glucagon observed 6-7 h after SMS 201-995 injection in the present study could hardly be attributed to the drug itself owing to the negligeable SMS 201-995 circulating levels at this time. In a preliminary study, performed in Type 1 diabetic patients, we showed that a $50 \mu \mathrm{g}$ s.c. injection of SMS 201-995 at 23.00 hours abolished midnight $\mathrm{GH}$ peaks and significantly reduced plasma glucagon levels until 04.00 hours [28]. Johnston et al. [29] reported similar results in normal subjects. Thus, the hormonal changes induced by a single s.c. injection of SMS 201-995 or a continuous i.v. infusion of native somatostatin appear to be similar both in healthy volunteers $(27,29,30)$ and in Type 1 diabetic patients [16, 31].

The injection of $50 \mu \mathrm{g}$ SMS 201-995 at 23.00 hours induced an early and marked decrease in blood glucose levels. As previously discussed [12], this early fall in blood glucose is unlikely to be due to inhibition of $\mathrm{GH}$ secretion [32], but more likely results from the early decrease in plasma glucagon levels. Inhibition of pancreatic glucagon secretion has been shown indeed to play an important role in the lowering of blood glucose concentrations by somatostatin [33]. In contrast with previous studies, in which SMS 201-995 was injected before a meal $[16,31]$, a significant interference with carbohydrate absorption [34] or with food-induced changes in gut hormones [35] is probably less important in the present study since SMS 201-995 was injected $5 \mathrm{~h}$ after the last meal.

The secondary rise in blood glucose levels from 02.00 to 05.00 hours could be explained by different mechanisms. It could be essentially attributed to the substantial insulin deficiency which occurred during the last $3 \mathrm{~h}$ of CSII interruption. Moreover, a progressively decreasing effect of SMS 201-995 could be suspected. Several studies reported that the metabolic effect of the drug decreases $4-5$ hours after s.c. injection [29-31], a finding in agreement with the pharmacokinetic data. Finally, there could be a counter-regulatory response to the early hypoglycaemia; seven out of nine patients exhibited after SMS 201-995 blood glucose values below $3 \mathrm{mmol} / 1$ and five below $2.5 \mathrm{mmol} / 1$ between 23.00 and 02.00 hours. Under these conditions, catecholamines and cortisol secretion, although not measured in the present study, are likely to be stimu- lated, since secretion of both $\mathrm{GH}$ and glucagon was inhibited by SMS 201-995 [36].

Confirming our previous data with i.v. infusion of somatostatin [12], SMS 201-995 did not significantly modify the early increase but significantly reduced the late rise in plasma 3-OHB levels during CSII interruption. Probably due again to the waning effect of SMS 201-995 3 to $4 \mathrm{~h}$ after its s.c. injection, this favourable effect was less pronounced than that observed with i.v. native somatostatin, which resulted in a complete blockade of the late rise in 3-OHB levels [12]. As previously discussed [12], the initial increase in plasma 3OHB levels after stopping the pump appears mainly to be secondary to the decrease in free insulin circulating levels while the late increase seems dependent, at least in part, on the glucagon and GH plasma levels. This view is in agreement with the current role of glucagon [37] and $\mathrm{GH}$ [38] in ketogenesis, particularly in a state of insulin deprivation [33] as observed 3-6 h after interruption of the CSII. The progressive increase in plasma NEFA and glycerol levels induced by the 6-h arrest of the pump was not significantly reduced by SMS 201995 , suggesting that the stimulation of lipolysis in our experimental conditions is mainly due to the insulin deprivation.

Two types of pumps were used in the present study. In fact, the metabolic deterioration induced by the 6-h CSII interruption in the control test was reduced in the group of patients using the Nordisk infuser when compared to that observed in the group of patients using the Mill Hill infuser. This finding was probably due to the higher insulin concentration within the Nordisk pump $(100 \mathrm{U} / \mathrm{ml})$ than that within the Mill Hill infuser $(20 \pm 2 \mathrm{U} / \mathrm{ml})$. Indeed, we have recently reported [39] that when the patients using the Nordisk pump with the U-100 insulin cartridge, as in the present study, underwent another 6-h CSII interruption test after having diluted U-100 insulin with $0.9 \% \mathrm{NaCl}$ to a final concentration of $20 \mathrm{U} / \mathrm{ml}$, an earlier decrease in plasma-free insulin levels and a significantly greater increase in blood glucose and plasma 3-OHB levels were observed. We hypothesized that the relative protection against such metabolic deterioration provided by U-100 insulin may be due to a steady-state s.c. depot containing a greater amount of insulin [39]. The differences between the two types of pumps observed in the control tests persisted in the SMS 201-995 tests. The most obvious difference between the two groups was the clear-cut reduction by SMS 201-995 of the late rise of plasma 3-OHB levels in the Mill Hill but not in the Nordisk group. These results again could suggest that the glucagon- and GHmediated inhibitory effects of SMS 201-995 on plasma 3-OHB levels were significant only when ketogenesis was markedly stimulated by severe insulinopenia.

The risk for early severe hypoglycaemia after SMS 201-995 was not influenced either by the type of pump or by the presence of autonomic neuropathy in the 
present study. In fact, the most predictive factor was the blood glucose level at the time of the SMS 201-995 injection since the five patients showing blood glucose values $<2.5 \mathrm{mmol} / \mathrm{l}$ after Sandostatin had already significantly lower values at 23.00 hours. Thus, in view of our data, a s.c. bolus injection of $50 \mu \mathrm{g}$ SMS 201995 should not be recommended in Type 1 diabetic patients with initial blood glucose levels below $7 \mathrm{mmol} / \mathrm{l}$.

In agreement with the good tolerance already reported in diabetic patients [16, 28, 31] and in some [27] but not all $[29,30]$ healthy volunteers, no patient suffered gastrointestinal side-effects after $50 \mu \mathrm{g}$ SMS 201995 in our study.

In conclusion, a single s.c. injection of $50 \mu \mathrm{g}$ SMS 201-995 reduces significantly the metabolic alterations induced by a 6-h nocturnal CSII interruption, acting in a manner comparable to that previously reported with a continuous i.v. infusion of $250 \mu \mathrm{g} / \mathrm{h}$ somatostatin. However, in well-controlled diabetic patients, the risk of hypoglycaemia during the first $3 \mathrm{~h}$ following the injection of this dose of SMS 201-995 appears to be important despite the interruption of the insulin infusion. Appropriate changes such as reducing the dosage, delaying the time of injection or modifying the mode of administration may help to solve the problem.

\section{References}

1. Pickup JC, Keen H, Viberti GC, White MC, Kohner EM, Parsons JA, Alberti KGMM (1980) Continuous subcutaneous insulin infusion in the treatment of diabetes mellitus. Diabetes Care 3: $290-300$

2. Sonnenberg GE, Spraul M, Chantelau EA, Berger M (1985) Kontinuierliche subkutane Insulin-Infusionstherapie. Voraussetzungen, Indikationen und Risiken. Dtsch Med Wochenschr 110: 1859-1864

3. Bending JJ, Pickup JC, Keen H (1985) Frequency of diabetic ketoacidosis and hypoglycemic coma during treatment with continuous subcutaneous insulin infusion. Am J Med 79: 685-691

4. Kroc Collaborative Study Group (1984) Blood glucose control and the evolution of diabetic retinopathy and albuminuria: a preliminary multicentre trial. N Engl J Med 311: 365-372

5. Mecklenburg R, Benson F, Benson J, Fredlund P, Guinn T, Metz R, Nielsen R, Sannar C (1984) Acute complications associated with insulin infusion pump therapy. Report of experience with 161 patients. JAMA 252: 3265-3269

6. Peden NR, Braaten JT, McKendry JBR (1984) Diabetic ketoacidosis during long-term treatment with continuous subcutaneous insulin infusion. Diabetes Care 7:1-5

7. Henrivaux P, Scheen AI, Daubresse JC, Rinaldi AM, Lefèbvre PJ (1986) Incidence and severity of ketoacidosis due to technical problems during continuous subcutaneous insulin infusion. In: Proceedings of Cardiostim 86, Drug delivery systems and chronotherapy, Monaco, June, 1986

8. Scheen AJ, Henrivaux P, Jandrain B, Luyckx AS, Lefèbvre PJ (1985) Lack of systematic metabolic alterations after a one-hour interruption of continuous subcutaneous insulin infusion in type 1 diabetic patients. Diabetes Care 8:621-623

9. Scheen AJ, Castillo M, Jandrain B, Krzentowski G, Henrivaux P, Luyckx AS, Lefèbvre PJ (1984) Metabolic alterations after a two- hour nocturnal interruption of a continuous subcutaneous insulin infusion. Diabetes Care 7: 338-342

10. Krzentowski G, Scheen A, Castillo M, Luyckx AS, Lefèbvre PJ (1983) A 6-hour nocturnal interruption of a continuous subcutaneous insulin infusion. 1. Metabolic and hormonal consequences and scheme for a prompt return to adequate control. Diabetologia 24: $314-318$

11. Scheen AJ, Henrivaux P, Jandrain B, Lefèbvre PJ (1986) Anti-insulin antibodies and metabolic deterioration after interruption of continuous subcutaneous insulin infusion. Diabetes Care 9: 673-674

12. Scheen AJ, Krzentowski G, Castillo M, Lefèbvre PJ, Luyckx AS (1983) A 6-hour nocturnal interruption of a continuous subcutaneous insulin infusion. 2. Marked attenuation of the metabolic deterioration by somatostatin. Diabetologia $24: 319-325$

13. Bauer W, Briner U, Doepfner W, Haler R, Huguenin R, Marbach P, Petcher TJ, Pless J (1982) SMS 201-995: a very potent and selective octapeptide analogue of somatostatin with prolonged action. Life Sci 31: 1133-1140

14. Pless J, Bauer W, Briner U, Doepfner W, Marbach P, Maurer R, Petcher TJ, Reubi JC, Vonderscher J (1986) Chemistry and pharmacology of SMS 201-995, a long-acting octapeptide analogue of somatostatin. Scand J Gastroent 21 [Suppl 119]: 54-64

15. Kutz K, Nuesch E, Rosenthaler J (1986) Pharmacokinetics of SMS 201-995 in healthy subjects. Scand J Gastroent 21 [Suppl 119]: 65-72

16. Spinas GA, Bock A, Keller U (1985) Reduced postprandial hyperglycemia after subcutaneous injection of a somatostatin-analogue (SMS 201-995) in insulin-dependent diabetes mellitus. Diabetes Care 8: $429-435$

17. Ewing DJ, Borsey DQ, Bellavere F, Clarke BF (1981) Cardiac autonomic neuropathy in diabetes: comparison of measures of R-R interval variation. Diabetologia $21: 18-24$

18. Dole VP, Meinertz H (1960) Microdetermination of long chain fatty acids in plasma and tissues. $J$ Biol Chem 235: 2595-2599

19. Williamson DH, Mellanby J (1974) D-(-)-3-hydroxybutyrate. In: Bergmeyer HU (ed) Methods of enzymatic analysis. Verlag Chemie, Weinheim. Academic Press, New York San Francisco London, pp 1836-1839

20. Eggstein M, Kulhmann E (1974) Triglycerides and glycerol determination after alkaline hydrolysis. In: Bergmeyer HU (ed) Methods of enzymatic analysis, Vol 4. Academic Press, London, pp 1825-1831

21. Luyckx AS (1972) Immunoassays for glucagon. In: Lefèbvre PJ, Unger RH (eds) Glucagon, molecular physiology, clinical and therapeutic implications. Pergamon Press, Oxford, pp 285-298

22. Franchimont $P$ (1966) Le dosage des hormones hypophysaires somatotropes et gonadotropes et son application clinique. Thesis. Arscia A.S., Brussels, N. Maloine S.A., Paris

23. Nakagawa S, Nakayama H, Sasaki T, Yoshimo K, Yu Y, Shimozaki K, Aoki S, Mashimo K (1973) Simple method for the determination of serum free insulin levels in insulin-treated patients. Diabetes 22: 590-600

24. Heding LG (1975) Radioimmunological determination of human C-peptide in serum. Diabetologia 11: $541-548$

25. Christiansen HA (1970) A new method for determination of insulin binding immunoglobulins in insulin-treated diabetic patients. Horm Metabol Res 2: 187-188

26. Schoos R, Schoos-Barbette S, Lambotte C (1978) Dosage of hemoglobin $A_{1 c}$ by isoelectrofocusing. Clin Chim Acta 86: 61-65

27. del Pozo E, Neufeld M, Schlüter $K$, Tortosa F, Clarenbach $P$, Bieder E, Wendel L, Nüesch E, Marbash P, Cramer H, Kerp L (1986) Endocrine profile of a long-acting somatostatin derivative SMS 201-995. Study in normal volunteers following subcutaneous administration. Acta Endocrinol 111: 433-439

28. Scheen AJ, Gillet J, Guiot J, Henrivaux P, Jandrain B, Lefèbvre PJ (1986) Attempt to prevent the dawn phenomenon by a bedtime subcutaneous injection of a somatostatin analogue (SMS 201-995) in Type-1 (insulin-dependent) diabetic patients. Diabetologia 29: 590-591 (Abstract) 
29. Johnston DG, Davies RR, Turner SJ (1986) Effects of somatostatin and SMS 201-995 on carbohydrate metabolism in normal man. Scand J Gastroent 21 [Suppl 119]: 158-165

30. Davies RR, Miller M, Turner SJ, Goodship THJ, Cook DB, Watson M, McGill A, Ørskov H, Alberti KGMM, Johnston DG (1986) Effects of somatostatin analogue SMS 201-995 in normal man. Clin Endocrinol 24: 665-674

31. Serrano-Rios M, Navascues I, Saban J, Ordonez A, Sevilla F, del Pozo E (1986) Somatostatin analog SMS 201-995 and insulin needs in insulin-dependent diabetic patients studied by means of an artificial pancreas. J Clin Endocrinol Metab 63: 1071-1074

32. MacGorman LR, Rizza RA, Gerich JE (1981) Physiological concentrations of growth hormone exert insulin-like and insulin antagonistic effects of both hepatic and extrahepatic tissues in man. J Clin Endocrinol Metab 53: 556-559

33. Gerich JE, Lorenzi M, Bier DM, Tsalikian E, Schneider V, Karam $\mathrm{JH}$, Forsham PH (1976) Effects of physiological levels of glucagon and growth hormone on human carbohydrate and lipid metabolism. Studies involving administration of exogenous hormone during suppression of endogenous hormone secretion with somatostatin. J Clin Invest 57:875-884

34. Johansson C, Wisen O, Efendic J, Uvnas-Wallensten K (1981) Effects of somatostatin on gastrointestinal propagation and absorption of oral glucose in man. Digestion 22: 126-137

35. Williams G, Fuessl H, Kraenzlin M, Bloom SR (1986) Postprandial effects of SMS 201-995 on gut hormones and glucose tolerance. Scand J Gastroent 21 [Suppl 119]: 73-83
36. Rosak C, Althoff PH, Fassbinder W, del Pozo E, Boehm BO (1986) Veränderungen der hormonellen Gegenregulation nach insulininduzierter Hypoglykämie bei gleichzeitiger Gabe des Somatostatinanalogons SMS 201-995. Med Klin 81: 773-778

37. McGarry JD, Foster DW (1980) Regulation of hepatic fatty acid oxidation and ketone body production. Ann Rev Biochem 49: $395-420$

38. Schade DS, Eaton RP, Peake GT (1978) The regulation of plasma ketone body concentration by counterregulatory hormones in man. II. Effect of growth hormone in diabetic man. Diabetes 27: 916-924

39. Scheen AJ, Henrivaux P, Jandrain B, Lefèbvre PJ (1987) U-100 insulin gives some protection against metabolic deterioration during CSII interruption. Diabetes Care 10:707-711

Received: 28 November 1988

and in revised form: 7 June 1989

Dr.P.Lefèbvre

Diabetes, Nutrition and Metabolic

Disorders Unit

C.H.U. Sart Tilman (B-35)

B-4000 Liège 1

Belgium 